\title{
SUPPORTING INFORMATION \\ Facile Solutions to the Problems Associated with Chemical Information and Mathematical Symbolism While Using Machine Translation Tools
}

\author{
M. Farooq Wahab ${ }^{\mathrm{a}}$, Sonia Zulfiqar ${ }^{\mathrm{b}}$, Muhammad Ilyas Sarwar ${ }^{\mathrm{c}}$, and Ingo Lieberwirth ${ }^{\mathrm{d}}$ \\ ${ }^{a}$ Department of Chemistry \& Biochemistry, University of Texas at Arlington,76019, USA \\ ${ }^{b}$ Department of Chemistry, School of Sciences \& Engineering, The American University in \\ Cairo, New Cairo, 11835, Egypt \\ ${ }^{c}$ Department of Chemistry, Quaid-i-Azam University, Islamabad 45320, Pakistan \\ ${ }^{d}$ Max Planck Institute for Polymer Research, Ackermannweg 10, 55128 Mainz, Germany
}

Corresponding Authors

M. Farooq Wahab: mfwahab@uta.edu or mwahab@ualberta.ca

Sonia Zulfiqar: sonia.zulfiqar@aucegypt.edu 


\section{TABLE OF CONTENTS}

\begin{tabular}{|l|l|}
\hline Sections & Page \\
\hline $\begin{array}{l}\text { A. Table S1. A list of major French and German publications that contain } \\
\text { significantly use information in chemistry and physics }\end{array}$ & $\mathrm{S} 3$ \\
\hline B. A German passage adapted from Zeitschrift für Naturforschung & $\mathrm{S} 4$ \\
\hline $\begin{array}{l}\text { C. Method III. Loss of formatting and incorrect machine translations with } \\
\text { routine approaches. An example of Google Translate: Direct cutting and } \\
\text { pasting of the text into the translation box }\end{array}$ & $\mathrm{S} 5$ \\
\hline $\begin{array}{l}\text { D. Method III. for DeepL translation: Direct cutting and pasting of the text into } \\
\text { the translation box }\end{array}$ & $\mathrm{S6}$ \\
\hline \begin{tabular}{l} 
E. Method IV. German translation by direct file upload option using DeepL \\
\hline \begin{tabular}{l} 
E. Human translation of the same German passage in section B. \\
\hline F. Method V applied on A French passage adapted from Physica as shown in \\
Table S2
\end{tabular}
\end{tabular} & $\mathrm{S} 7$ \\
\hline G. Method IV. French translation by direct upload option using DeepL & $\mathrm{S} 8$ \\
\hline
\end{tabular}


A. Table S1. A list of major French and German publications that contain significant material in chemistry and physics

\begin{tabular}{|c|c|}
\hline \multicolumn{2}{|c|}{ Major French journals and publications } \\
\hline & Comments \\
\hline Comptes rendus de l'Académie des Sciences & Published since 1666 under various names \\
\hline Annales de chimie et de physique & Published since 1789 under various names \\
\hline Bulletin de la Société Chimique de France & $\begin{array}{l}\text { Published by the French Chemical Society } \\
\text { for more than } 100 \text { years }(1858-1997)\end{array}$ \\
\hline Bulletin des Sociétés Chimiques Belges & $\begin{array}{l}\text { Published by the Chemical Society of } \\
\text { Belgium (1904-1997) }\end{array}$ \\
\hline Journal de Chimie Physique & Physical Chemistry Journal 1903 until 1999 \\
\hline Recueil des Travaux Chimiques des Pays-Bas & Published by Netherlands $1882-1996$ \\
\hline \multicolumn{2}{|c|}{ Major German journals and publications } \\
\hline $\begin{array}{l}\text { Beilstein Handbuch der Organischen Chemie and } \\
\text { Gmelin Handbuch der Anorganische Chemie }\end{array}$ & $\begin{array}{l}\text { Largest database of organic and inorganic } \\
\text { compounds known today (merged by } \\
\text { Reaxys of Elsevier) }\end{array}$ \\
\hline Angewandte Chemie (German Chemical Society) & $\begin{array}{l}\text { Publishes articles in mainly organic/ } \\
\text { inorganic synthesis and material science }\end{array}$ \\
\hline Annalen der Physik & $\begin{array}{l}\text { Contains significant discoveries in physics } \\
\text { in the } 20^{\text {th }} \text { century }\end{array}$ \\
\hline Fresenius' Zeitschrift für Analytische Chemie & $\begin{array}{l}\text { Appears as Analytical \& Bioanalytical } \\
\text { Chemistry }\end{array}$ \\
\hline Chemische Berichte & $\begin{array}{l}\text { A major source of synthetic organic } \\
\text { chemistry }\end{array}$ \\
\hline Methoden der Organischen Chemie, Houben-Weyl & $\begin{array}{l}\text { Leading resource of reliable organic } \\
\text { reactions and techniques spanning a century }\end{array}$ \\
\hline Zeitschrift für Physikalische Chemie & $\begin{array}{l}\text { A major physical chemistry journal initiated } \\
\text { by Ostwald }\end{array}$ \\
\hline $\begin{array}{l}\text { Miscelleneous journals: Journal für praktische Chemie, } \\
\text { Microchimica Acta, Zeitschrift für anorganische und } \\
\text { allgemeine Chemie etc. }\end{array}$ & $\begin{array}{l}\text { German and English, all these journals } \\
\text { publish in English now }\end{array}$ \\
\hline $\begin{array}{l}\text { Tetrahedron Letters, Carbohydrate Research, Analytica } \\
\text { Chimica Acta, Talanta, Journal of Chromatography A, } \\
\text { very old issues of Journal of the American Chemical } \\
\text { Society, and many other Elsevier journals, Numerous } \\
\text { Lehrbücher (textbooks) }\end{array}$ & $\begin{array}{l}\text { Mainly English but occassionally French/ } \\
\text { German articles also appeared in older } \\
\text { volumes }\end{array}$ \\
\hline
\end{tabular}




\section{B. [A German Passage Adapted from Zeitschrift für Naturforschung A 8.7 (1953): 448-450]}

„Im Folgenden wird ein Massenspektrometer beschrieben, welches nur ein quasistationäres elektrisches Wechselfeld benutzt, bei dem der Betrag der Feldstärke proportional dem Abstand von einer vorgegebenen Geraden, z.B. der z-Achse, ist. Derartige Felder $|F| \sim r^{m}$ wurden in statischer Form von Scherzer zur Korrektur von Elektronenlinsen verwendet, während Friedburg und Paul ein entsprechendes statisches Magnetfeld zur Fokussierung neutraler Atome benutzten. Ein magnetisches Vierpolfeld mit räumlicher Periodizität zur Fokussierung von Protonen wurde vor kurzem von Courant, Livingston und Snyder angegeben.

Die Ionen werden in z-Richtung in ein Feld mit dem Potential

$$
\varphi(x, y, t)=\frac{U+V \cos \omega t}{a^{2}} \cdot \frac{\left(x^{2}-y^{2}\right)}{2}
$$

eingeschossen. Dieses Feld wird erzeugt durch vier hyperbelförmige Elektroden mit dem Abstand a von der z-Achse, die abwechselnd an der Spannung

$$
\pm \frac{1}{2}(U+V \cos \omega t)
$$

liegen, d.h. zwischen zwei benachbarten Elektroden liegt jeweils eine Gleichspannung $U$ und eine Wechselspannung Vcoswt. Die Bewegungsgleichungen für ein Ion der Ladung e und Masse M lauten dann

b) $\ddot{y}-\frac{e}{M a^{2}}(U+V \cos \omega t) y=0$,

$$
\text { a) } \ddot{x}+\frac{e}{M a^{2}}(U+V \cos \omega t) x=0
$$

c) $\ddot{z}=0$.

(2c) hat die triviale Lösung $v_{z}=\dot{z}=$ const. (2a) geht durch die Substitution

$$
\omega t=2 \zeta, \quad \frac{4 e U}{M a^{2} \omega^{2}}=\lambda, \quad \frac{4 e V}{M a^{2} \omega^{2}}=q
$$

über in die Mathieu-Gleichung

$$
\frac{d^{2} x}{d \zeta^{2}}+(\lambda+q \cos 2 \zeta) x=0
$$

Diese Gl. (3) hat nur in gewissen Bereichen der Parameter $\lambda$ und q sog. ,stabile “Lösungen, d.h. Lösungen, die bei beliebigen Anfangsbedingungen für alle Werte von $\zeta$ beschränkt bleiben. Außerhalb dieser Stabilitätsbereiche wachsen die allgemeinen Lösungen exponentiell mit $\zeta$ an, d.h. die betreffenden Ionen werden schon nach kurzer Zeit auf die Elektroden fliegen. “ 


\section{Loss of Formatting and Incorrect Machine Translations with Routine Approaches}

[Google Translate: Direct cutting and pasting of the text into the translation box (accessed $14^{\text {th }}$ March 2020)]

"The following describes a mass spectrometer that uses only a quasi-stationary alternating electric field, in which the magnitude of the field strength is proportional to the distance from a given straight line, e.g. the $\mathrm{z}$-axis. Such fields $|\mathrm{F}| \sim \mathrm{r}^{\wedge} \mathrm{m}$ were used in a static form by Scherzer for the correction of electron lenses, while Friedburg and Paul used a corresponding static magnetic field to focus neutral atoms. A magnetic four-pole field with spatial periodicity for focusing protons was recently given by Courant, Livingston and Snyder.

The ions are in the $\mathrm{z}$ direction in a field with the potential

$\varphi(\mathrm{x}, \mathrm{y}, \mathrm{t})=\left(\mathrm{U}+\mathrm{V} \cos f_{0} \llbracket(\omega \mathrm{t} \rrbracket) / \mathrm{a}^{\wedge} 2 .\left(\left(\mathrm{x}^{\wedge} 2-\mathrm{y}^{\wedge}(2)\right)\right) / 2(1)\right.$

shot in. This field is generated by four hyperbolic electrodes spaced a from the z-axis, which alternate in voltage

$\pm 1 / 2\left(U+V \cos _{L-1}^{i} f_{0}\right][(\omega t))$

lie, i.e. A DC voltage $\mathrm{U}$ and an $\mathrm{AC}$ voltage $\mathrm{V} \cos \omega t$ are located between two adjacent electrodes. The equations of motion for an ion of charge e and mass $\mathrm{M}$ are then

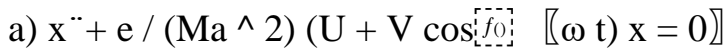

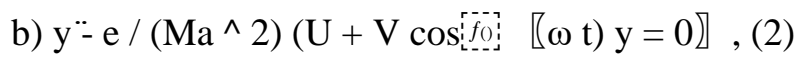

c) $z^{\prime \prime}=0$.

(2c) has the trivial solution $\square \mathrm{z}=\dot{\mathrm{z}}=$ const. (2a) goes through the substitution

$\omega \mathrm{t}=2 \zeta,(4 \mathrm{e} \mathrm{U}) /\left(\mathrm{Ma}^{\wedge}(2) \omega^{\wedge} 2\right)=\square,(4 \mathrm{e} \mathrm{V}) /\left(\mathrm{Ma}^{\wedge}(2) \omega^{\wedge} 2\right)=\mathrm{q}$

over into the Mathieu equation

$\left(\mathrm{d}^{\wedge} 2 \mathrm{x}\right) /(\mathrm{d} \zeta \wedge 2)+\left(\square+\mathrm{q} \cos _{\llcorner}^{[1} f_{0}\right] \quad[2 \zeta) \mathrm{x}=0 .(3) \rrbracket$

This Eq. (3) has so-called "stable" solutions only in certain areas of the parameters $\lambda$ and q, i.e. Solutions that remain restricted to all values of bei under any initial conditions. Outside of these stability ranges, the general solutions grow exponentially with $\zeta$, i.e. the ions in question will fly onto the electrodes after a short time. " 


\section{DeepL translation: Direct Cutting and Pasting of the Text into the Translation Box [DeepL translation (accessed 14 ${ }^{\text {th }}$ March 2020)]}

" In the following, a mass spectrometer is described which uses only a quasi-stationary alternating electric field in which the magnitude of the field strength is proportional to the distance from a given straight line, e.g. the $\mathrm{z}$-axis. Such fields $|\mathrm{F}| \sim \mathrm{r}^{\wedge} \mathrm{m}$ were used in static form by Scherzer to correct electron lenses, while Friedburg and Paul used a corresponding static magnetic field to focus neutral atoms. A four-pole magnetic field with spatial periodicity for focusing protons was recently given by Courant, Livingston and Snyder.

The ions are transformed in the z-direction into a field with the potential

$\varphi(\mathrm{x}, \mathrm{y}, \mathrm{t})=(\mathrm{U}+\mathrm{V} \cos \mathrm{t} \rrbracket) / \mathrm{a}^{\wedge} 2 \cdot\left(\left(\mathrm{x}^{\wedge} 2-\mathrm{y}^{\wedge}(2)\right)\right) / 2(1)$

shot in. This field is generated by four hyperbolic electrodes with the distance a from the z-axis, which are alternately connected to the voltage

$\pm 1 / 2(\mathrm{U}+\mathrm{V} \rrbracket \mathrm{t}) \rrbracket$

i.e. between two adjacent electrodes there is a direct voltage $U$ and an alternating voltage Vcos $\omega t$. The equations of motion for an ion of charge e and mass $M$ are

(a) $\left.x^{\ddot{2}}+\mathrm{e} /\left(\mathrm{Ma}^{\wedge} 2\right)(\mathrm{U}+\mathrm{V} \cos \mathrm{t}) \mathrm{x}=0\right)$

(b) $y^{\prime \prime}-e /\left(M a^{\wedge} 2\right)(U+V “ t) y=0 \rrbracket,(2)$

c) $\mathrm{z}=0$.

(2c) has the trivial solution $z=\dot{z}=$ const. (2a) goes through the substitution

$\omega \mathrm{t}=2 \zeta,(4 \mathrm{e} \mathrm{U}) /\left(\mathrm{M} \mathrm{a}^{\wedge}(2) \omega^{\wedge} 2\right)=,(4 \mathrm{e} \mathrm{V}) /\left(\mathrm{M} \mathrm{a}^{\wedge}(2) \omega^{\wedge} 2\right)=\mathrm{q}$

over into the Mathieu equation

$\left.\left(d^{\wedge} 2 x\right) /\left(d \zeta^{\wedge} 2\right)+(+q \cos ) x=0 .(3)\right]$

This eq. (3) only has so-called "stable" solutions in certain ranges of the parameters $\lambda$ and q, i.e. solutions that remain restricted for all values of $\zeta$ under any initial conditions. Outside these stability ranges, the general solutions grow exponentially with $\zeta$, i.e. the ions concerned will fly onto the electrodes after a short time". 


\section{E. [Direct file translation using DeepL Pro- Accessed 18May 2020] A new mass spectrometer without magnetic field}

\section{A new mass spectrometer without magnetic field}

In the following, a mass spectrometer is described which uses only a quasi-stationary alternating electric field in which the magnitude of the field strength is proportional to the distance from a given straight line, e.g. the z-axis. Such fields $|\mathrm{F}| \sim \mathrm{r}^{\mathrm{m}}$ were used in static form by Scherzer to correct electron lenses, while Friedburg and Paul used a corresponding static magnetic field to focus neutral atoms. A four-pole magnetic field with spatial periodicity for focusing protons has recently been specified by Courant, Livingston and Snyder.

In the $z$-direction, the ions are introduced into a field with the potential

$$
\varphi(x, y, t)=\frac{U+V \cos \omega t}{a^{2}} \cdot \frac{\left(x^{2}-y^{2}\right)}{2}
$$

....shot at. This field is generated by four hyperbola-shaped electrodes with the distance $a$ from the $z$-axis, which are alternately connected to the voltage

$$
\pm \frac{1}{2}(U+V \cos \omega t)
$$

i.e. between two adjacent electrodes there is a direct voltage $U$ and an alternating voltage Vcos $\omega t$. The equations of motion for an ion of charge e and mass $M$ then read

$$
\begin{aligned}
& \text { a) } \ddot{x}+\frac{e}{M a^{2}}(U+V \cos \omega t) x=0 \\
& \text { b) } \ddot{y}-\frac{e}{M a^{2}}(U+V \cos \omega t) y=0,
\end{aligned}
$$

c) $\ddot{z}=0$.

(2c) has the trivial solution $v_{z}=\dot{z}=$ const. (2a) goes through the substitution

$$
\omega t=2 \zeta, \quad \frac{4 e U}{M a^{2} \omega^{2}}=\lambda, \quad \frac{4 e V}{M a^{2} \omega^{2}}=q
$$

over into the Mathieu equation

$$
\frac{d^{2} x}{d \zeta^{2}}+(\lambda+q \cos 2 \zeta) x=0
$$

This eq. (3) has only in certain areas of the parameters $\lambda$ and q so called "stable" solutions, i.e. solutions which are stable under any initial conditions for all values of $\zeta$ remain limited. Outside these stability areas, the general solutions grow exponentially with $\zeta$ i.e. the ions concerned will fly onto the electrodes after a short time. 


\section{F. [German Speaker's Approved Translation] A new mass spectrometer without magnetic field}

In the following, a mass spectrometer will be described, which uses only a quasi-stationary alternating electric field in which the amount of field strength is proportional to the distance from a given line, e.g., the $z$-axis is. Such fields $|\mathrm{F}| \sim r^{\mathrm{m}}$ were used in static form by Scherzer for correction of electron lenses, while Friedburg and Paul used a corresponding static magnetic field for focusing neutral atoms. A magnetic four pole (quadrupole) field with spatial periodicity for focusing protons was recently reported by Courant, Livingston and Snyder.

In z-direction, the ions were injected into a field with potential

$$
\varphi(x, y, t)=\frac{U+V \cos \omega t}{a^{2}} \cdot \frac{\left(x^{2}-y^{2}\right)}{2}
$$

This field is generated by four hyperbolic electrodes with the distance $a$ from the $z$-axis, which lie alternating at voltage

$$
\pm \frac{1}{2}(U+V \cos \omega t)
$$

i.e., between two adjacent electrodes is in each case a DC voltage $U$ and an AC voltage $V \cos \omega t$. The equations of motion for an ion of charge $e$ and mass $M$ are then

a) $\ddot{x}+\frac{e}{M a^{2}}(U+V \cos \omega t) x=0$

b) $\quad \ddot{y}-\frac{e}{M a^{2}}(U+V \cos \omega t) y=0$,

c) $\ddot{z}=0$.

(2c) has the trivial solution $v_{z}=\dot{z}=$ const . (2a ) transforms by substitution

$$
\omega t=2 \zeta, \quad \frac{4 e U}{M a^{2} \omega^{2}}=\lambda, \quad \frac{4 e V}{M a^{2} \omega^{2}}=q
$$

into the Mathieu-equation

$$
\frac{d^{2} x}{d \zeta^{2}}+(\lambda+q \cos 2 \zeta) x=0
$$

This Eqs. (3) only has so-called "stable" solutions in certain ranges of the parameters $\lambda$ and $q$ i.e., solutions that remain limited for all values of $\zeta$ under any initial conditions. Outside these stability regions, the general solutions grow exponentially with $\zeta$ i.e., the ions in question will fly onto the electrodes in a short time. 


\title{
G. Original French Passage shown in the Manuscript
}

\section{L’interaction entre les atomes magnétogènes dans un cristal paramagnetique}

\author{
par H. A. KRAMERS \\ Université d'Utrecht
}

Théorème général sur la nature de l'interaction

Soit un cristal dans son état fondamental composé d'un grand nombre $K$ d'atomes dans un état doublement dégénéré, ainsi que d'un grand nombre $N$ d'atomes dans un état simple. Nous désignons les différents atomes de la première espèce, dont chacun contient un nombre impair d'électrons, par l'indice $k(k=1,2 \ldots . K)$, ceux de la seconde espèce, qui contiennent tous un nombre pair d'électrons, par l'indice $n(n=1,2 \ldots . N)$. Désignons par $\varphi_{k}^{t}$ les fonctions d'onde normalisées à l'aide desquelles on décrit l'état de l'atome $k$, où t pourra prendre les valeurs $1 / 2$ et$1 / 2$; soit $\chi_{n}$ la fonction d'onde normalisée de l'atome $n$.

Nous définissons la fonction spin-conjuguée» d'une fonction $\varphi_{s_{1}}, s_{2} \ldots\left(x_{1} y_{1} z_{1} x_{2} \ldots\right)$ qui dépend des coördonnées de l'espace $x_{1}, y_{1}, z_{1}, x_{2}, \ldots$ ainsi que des coördonnées spin $s_{1}, s_{2} \ldots d^{\prime}$ un nombre $p$ d'électrons par la règle :

$\bar{\varphi}_{s_{1}, s_{2}} \ldots=(-1)^{\sum s_{m-p / 2}} \varphi_{-s_{1},-s_{2}}^{*} \cdots$,

où $\varphi^{*}$ signifie le complexe-conjugué de $\varphi$. Pour un choix déterminé de $\varphi_{k}^{1 / 2}$ il sera alors permis de définir $\varphi_{k}^{-1 / 2}$ comme la fonction spin-conjuguée de $\varphi_{k}^{1 / 2}$.

$\varphi_{k}^{-1 / 2}=\overline{\varphi_{k}^{1 / 2}}$

Du fait de l'absence d'un champ magnétique extérieur, cette fonction (2) satisfait à l'équation de Schrödinger au même temps que $\varphi_{k}^{1 / 2}$. Les moments magnétiques de l'atome dans les deux états correspondants sont égaux mais de signe opposé. 
$\underline{\text { Table S2. Dummy variable approach for the French passage in the main manuscript }}$

\begin{tabular}{|c|c|c|c|}
\hline variable & Representation & Variable & Representation \\
\hline [F1] & $k(k=1,2 \ldots K)$ & [F10] & $s_{1}, s_{2} \ldots$ \\
\hline [F2] & $n(n=1,2 \ldots \mathrm{N})$. & [F11] & $p$ \\
\hline [F3] & $\varphi_{k}^{t}$ & [F12] & equation (1) \\
\hline [F4] & $k$ & [F13] & $\varphi^{*}$ \\
\hline [F5] & $t$ & [F14] & $\varphi$ \\
\hline [F6] & $\chi_{n}$ & [F15] & $\varphi_{k}^{1 / 2}$ \\
\hline [F7] & $n$ & [F16] & $\varphi_{k}^{-1 / 2}$ \\
\hline [F8] & $\varphi_{s_{1}}, s_{2} \ldots\left(x_{1} y_{1} z_{1} x_{2} \ldots\right)$ & {$[$ F17] } & equation (2) \\
\hline [F9] & $x_{1}, y_{1}, z_{1}, x_{2}, \ldots$ & & \\
\hline
\end{tabular}

\title{
L'interaction entre les atomes magnétogènes dans un cristal paramagnetique
}

\author{
par H. A. Kramers
}

Université d'Utrecht

[Corrected 13 March 2020]

Théorème général sur la nature de l'interaction

Soit un cristal dans son état fondamental composé d'un grand nombre $K$ d'atomes dans un état doublement dégénéré, ainsi que d'un grand nombre $N$ d'atomes dans un état simple. Nous désignons les différents atomes de la première espèce, dont chacun contient un nombre impair d'électrons, par l'indice [F1], ceux de la seconde espèce, qui contiennent tous un nombre pair d'électrons, par l'indice [F2]. Désignons par [F3] les fonctions d'onde normalisées à l'aide desquelles on décrit l'état de l'atome [F4], où [F5] pourra prendre les valeurs 1/2 et —1/2; soit [F6] la fonction d'onde normalisée de l'atome [F7].

Nous définissons la "fonction spin-conjuguée » d'une fonction [F8] qui dépend des coördonnées de l'espace [F9] ainsi que des coördonnées spin [F10] d'un nombre [F11] d'électrons par la règle : [F12], où [F13] signifie le complexe-conjugué de [F14]. Pour un choix déterminé de [F15] il sera alors permis de définir [F16] comme la fonction spin-conjuguée de [F15]. [F17].

Du fait de l'absence d'un champ magnétique extérieur, cette fonction (2) satisfait à l'équation de Schrödinger au même temps que [F15]. Les moments magnétiques de l'atome dans les deux états correspondants sont égaux mais de signe opposé. 
Google Translate (Accessed 13th March, 2020)

General theorem on the nature of the interaction

Consider a crystal in its ground state composed of a large number $\mathrm{K}$ of atoms in a doubly degenerate state, as well as a large number $\mathrm{N}$ of atoms in a simple state. We denote the different atoms of the first species, each of which contains an odd number of electrons, by the index [F1], those of the second species, which all contain an even number of electrons, by the index [F2 ]. Let us denote by [F3] the normalized wave functions with the help of which we describe the state of the atom [F4], where [F5] can take the values $1 / 2$ and $-1 / 2$; let [F6] be the normalized wave function of the atom [F7].

We define the "spin-conjugate function" of a function [F8] which depends on the space coordinates [F9] as well as the spin coordinates [F10] of a number [F11] of electrons by the rule: [F12], where [F13] means the complex-conjugate of [F14]. For a determined choice of [F15] it will then be possible to define [F16] as the spin-conjugate function of [F15]. [F17].

Due to the absence of an external magnetic field, this function (2) satisfies the Schrödinger equation at the same time as [F15]. The magnetic moments of the atom in the two corresponding states are equal but of opposite sign. 


\title{
H. Direct Translation of the French Text from (H.A. Kramers) by Uploading the Word File in DeepL Pro (Accessed 23June 2020).
}

\section{The interaction between magnetogenic atoms in a paramagnetic crystal}

\author{
by H. A. KRAMERS \\ Utrecht University
}

\section{General Theorem on the Nature of Interaction}

Let a crystal in its fundamental state composed of a large number $K$ of atoms in a doubly degenerate state and a large number $N$ of atoms in a single state. We designate the different atoms of the first species, each of which contains an odd number of electrons, by the index $k(k=$ $1,2 \ldots . \mathrm{K})$, those of the second species, which all contain an even number of electrons, by the index $n(n=1,2 \mathrm{~N} \ldots . .$.$) . Let us denote by \varphi_{\mathrm{k}}^{\mathrm{t}}$ the normalized wave functions by means of which the state of the atom $k$ is described, where $t$ may take the values $1 / 2$ and-1/2; or $\chi_{n}$ the normalized wave function of the $n$ atom.

We define the "spin-conjugate function" of an $\varphi_{\mathrm{s}_{1}, \mathrm{~s}_{2} \ldots . .}\left(\mathrm{x}_{1} \mathrm{y}_{1} \mathrm{z}_{1} \mathrm{x}_{2} . . ..\right)$ which depends on the coordinates of space $\mathrm{x}_{1}, \mathrm{y}_{1}, \mathrm{z}_{1}, \mathrm{x}_{2}, .$. as well as spin coordinates $\mathrm{s}_{1}, \mathrm{~s}_{2}$. . of a number $p$ of electrons by the rule :

$\bar{\varphi}_{s_{1}, s_{2}} \ldots=(-1)^{\sum s_{m-p / 2}} \varphi_{-s_{1},-s_{2}}^{*} \cdots$,

where $\varphi^{*}$ means the conjugate complex of $\varphi$. For a given choice of $\varphi_{\mathrm{k}}^{1 / 2}$ it will then be allowed to define $\varphi_{\mathrm{k}}^{-1 / 2}$ such as the spin-conjugate function of $\varphi_{\mathrm{k}}^{1 / 2}$.

$\varphi_{\mathrm{k}}^{-1 / 2}=\overline{\varphi_{\mathrm{k}}^{1 / 2}}$

Due to the absence of an external magnetic field, this function (2) satisfies Schrödinger's equation at the same time as $\varphi_{\mathrm{k}}^{1 / 2}$. The magnetic moments of the atom in the two corresponding states are equal but of opposite sign.

$* * * *$

The word fundamental could better be rendered as "ground". The translation of "ground" vs. "fundamental" is random in DeepL. On certain days it was ground, and on other days it is "fundamental". The only main error in the translation in "or $\chi_{n}$ the normalized wave function..." should rather be "and $\chi_{n}$ the normalized wave function..." according to a French speaker. 